\title{
TOTAL COLONIC VOLVULUS WITH INCOMPLETE ROTATION OF THE GUT PRESENTING IN AN ADULT FEMALE
}

Dharmendra. B. L., Lakshmikantha. G.

1. Assistant Professor. Department of General Surgery, Mysore Medical College \& Research Institute, Mysore, Karnataka, India.

2. Assistant Professor. Department of Obstetrics \& Gynecology, Mysore Medical College \& Research Institute, Mysore, Karnataka, India.

\section{CORRESPONDING AUTHOR}

Dr. Lakshmikantha. G,

\# 249, $3^{\text {rd }}$ A main,

Near Amba Bhavani Circle,

NE of NR Mohalla, Mysore, Karnataka, India.

E-mail: drlakshmikanthag@yahoo.co.in

Ph: 00919740810611

INTRODUCTION: Although malrotation has long been recognized as a cause of intestinal obstruction in neonates $(1,2)$ its clinical importance in adults is less well documented. Incomplete gut rotation with total colonic volvulus in an adult is an uncommon type of intestinal volvulus causing acute obstruction.

KEY WORDS: Incomplete rotation of gut, Volvulus, Defunctioning ileostomy, Total Colectomy.

CASE REPORT: A 40-year old multiparous female patient presented with abdominal pain, distension and bilious vomiting, patient had not passed stools and flatus since one day. Her past medical history was not suggestive of any abdominal surgeries or associated illness. Examination revealed anemia, tachycardia, dehydration, abdominal distention, diffuse tenderness, guarding. Erect abdominal plain radiograph revealed multiple air fluid levels with large colonic gas shadows. With provisional diagnosis of acute intestinal obstruction, decision was taken to proceed with emergency exploratory laparotomy. On laparotomy there was grossly distended large bowel with volvulus of whole colon with entire colon being mobile with free mesentery with gangrene of whole colon up to distal caecum, proximal caecum and appendix was viable. Recto sigmoid junction located in right side of pelvis. Duodenum was fixed; Small intestine and rest of the abdominal organs were normally located. There was no evidence of any adhesions or congenital bands. Total colectomy and ileorectal anastomosis was done with defunctioning proximal loop ileostomy. Tube drain was inserted and abdominal wall closed in layers. Post- operative recovery was uneventful; the patient was discharged on $10^{\text {th }}$ day. Patient was readmitted after six weeks for closure of de functioning ileostomy after confirming patency of ileorectal anastomosis with barium enema. Closure of ileostomy done under spinal anesthesia. Patient was discharged and followed up for two months who showed uneventful recovery.

DISCUSSION: Incomplete rotation of gut represents a failure occurring during the final $180 \AA$ counterclockwise rotation of the small bowel and/or the final $180 \AA$ counterclockwise rotation of the colon often, this is confusingly termed "malrotation". Malrotation is a generic term used to describe the consequences. Simply defined, malrotation is a failure during development of normal rotation of any part of the intestinal tract (3). 
Errors of intestinal fixation, where ascending and descending colon fail to adhere to the posterior abdominal wall (4). These conditions are not only rare but difficult to accurately diagnose preoperatively. Abnormally rotated bowel does not develop a normal mesenteric attachment. The risk for volvulus varies with the degree of mesenteric attachment. There have been extensive studies and literature available about Intestinal malrotation with midgut volvulus in neonatal and pediatric age group but very few cases reported in adults. Total colonic volvulus in incomplete gut rotation in adults presenting with acute intestinal obstruction is rare.

CONCLUSION: Incomplete gut rotation with total colonic volvulus is an uncommon type of intestinal volvulus causing acute obstruction in adults.

\section{REFERENCES:}

1. Gross RE, The surgery of infancy and childhood, Philadelphia; WB Saunders Co,1953

2. McIntosh R. Donovan EJ. Disturbances of rotation of intestinal tract. Am J.Dis Child 1939;57:116-66

3. PeterJ.Strouse, Disorders of intestinal rotation and fixation. PediatrRadiol(2004) 34:837-851

4. Hugh WG,MichaelHT,ChristopherPA.annals of royal college of surgeons of England(1990) vol.72,239-242 


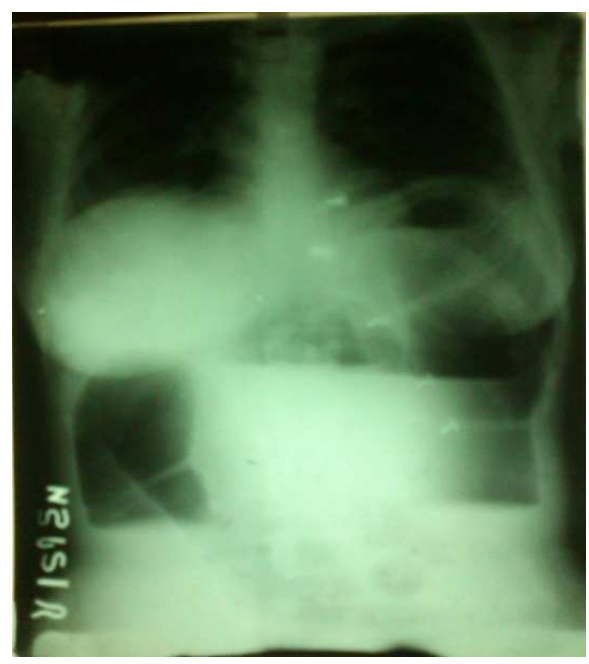

Fig.1 Erect radiograph of the patient

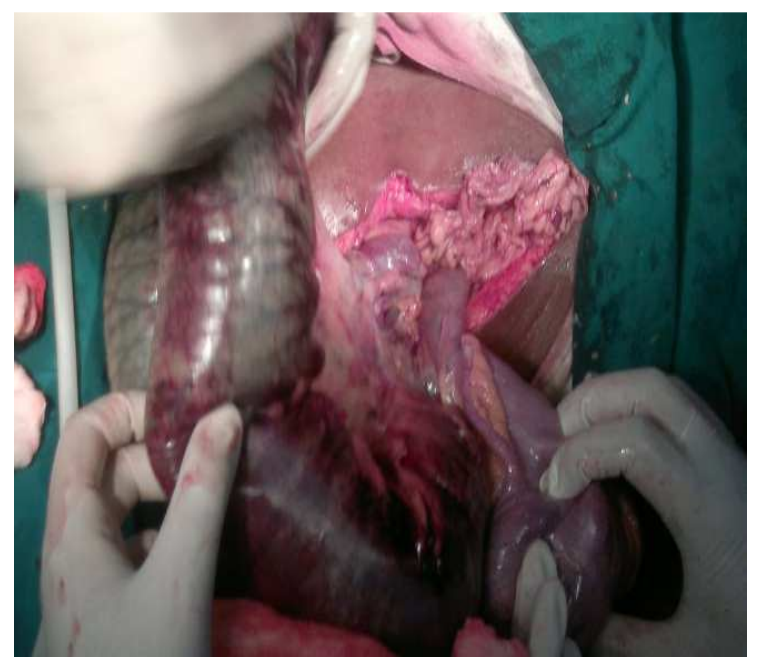

Fig.2 Volvulus and Gangrene of colon

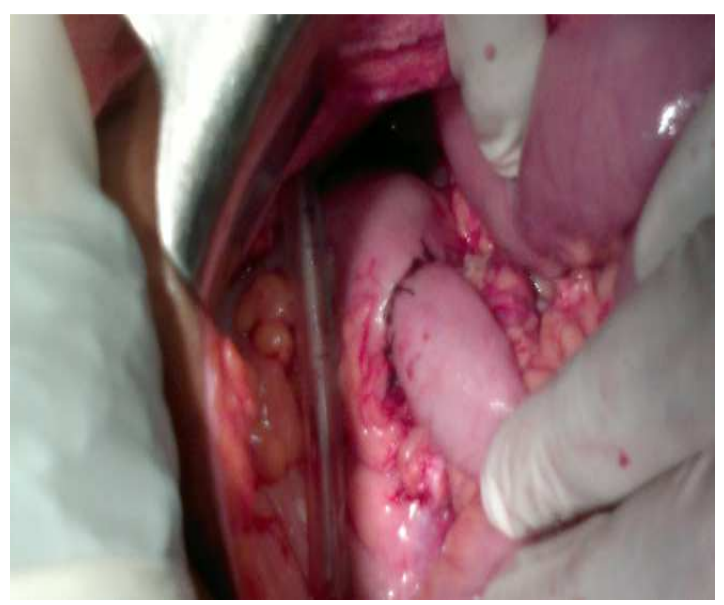

Fig.3 Ileorectal anastomosis

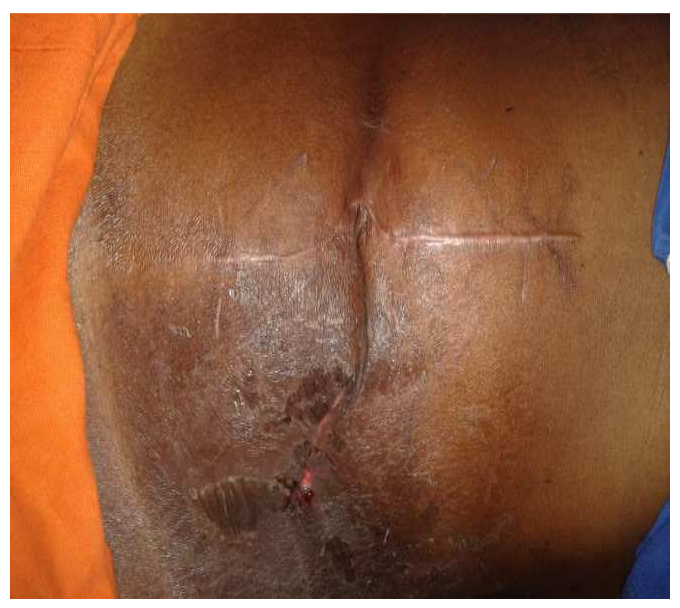

Fig.4 Healed wound after stoma closure 